\title{
The galactic cosmic ray intensity over the past 10(6)-10(9) years as recorded by cosmogenic nuclides in meteorites and terrestrial samples
}

\author{
Journal Article \\ Author(s): \\ Wieler, Rainer; Beer, Jürg; Leya, Ingo \\ Publication date: \\ 2013-06 \\ Permanent link: \\ https://doi.org/10.3929/ethz-b-000044468 \\ Rights / license: \\ In Copyright - Non-Commercial Use Permitted \\ Originally published in: \\ Space Science Reviews 176(1-4), https://doi.org/10.1007/s11214-011-9769-9
}




\title{
The Galactic Cosmic Ray Intensity over the Past $10^{6}-10^{9}$ Years as Recorded by Cosmogenic Nuclides in Meteorites and Terrestrial Samples
}

\author{
Rainer Wieler · Jürg Beer · Ingo Leya
}

Received: 4 October 2010 / Accepted: 15 March 2011 / Published online: 31 March 2011

(C) Springer Science+Business Media B.V. 2011

\begin{abstract}
Concentrations of stable and radioactive nuclides produced by cosmic ray particles in meteorites allow us to track the long term average of the primary flux of galactic cosmic rays (GCR). During the past $\sim 10 \mathrm{Ma}$, the average GCR flux remained constant over timescales of hundreds of thousands to millions of years, and, if corrected for known variations in solar modulation, also during the past several years to hundreds of years. Because the cosmic ray concentrations in meteorites represent integral signals, it is difficult to assess the limits of uncertainty of this statement, but they are larger than the often quoted analytical and model uncertainties of some $30 \%$. Time series of concentrations of the radionuclide ${ }^{10} \mathrm{Be}$ in terrestrial samples strengthen the conclusions drawn from meteorite studies, indicating that the GCR intensity on a $\sim 0.5$ million year scale has remained constant within some $\pm 10 \%$ during the past $\sim 10$ million years. The very long-lived radioactive nuclide ${ }^{40} \mathrm{~K}$ allows to assess the GCR flux over about the past one billion years. The flux over the past few million years has been the same as the longer-term average in the past $0.5-1$ billion years within a factor of $\sim 1.5$. However, newer data do not confirm a long-held belief that the flux in the past few million years has been higher by some $30-50 \%$ than the very long term average. Neither does our analysis confirm a hypothesis that the iron meteorite data indicate a $\sim 150$ million year periodicity in the cosmic ray flux, possibly related to variations in the long-term terrestrial climate.
\end{abstract}

Keywords Galactic cosmic ray intensity $\cdot$ Cosmogenic nuclides $\cdot$ Meteorites · Beryllium-10 in sediments $\cdot$ Exposure ages

R. Wieler (凶)

Institute of Geochemistry and Petrology, ETH Zürich, NW C84, 8092 Zürich, Switzerland e-mail: wieler@erdw.ethz.ch

J. Beer

Swiss Federal Institute of Aquatic Science and Technology, 8600 Dübendorf, Switzerland

I. Leya

Physikalisches Institut, Universität Bern, Sidlerstrasse 5, 3012 Bern, Switzerland 


\section{Introduction}

Meteorites have been exposed to the galactic cosmic radiation (GCR) since they were ejected from larger parent bodies. Stable and radioactive nuclides produced by interactions of cosmic ray particles (primary GCR particles are mainly protons and alpha particles) with target atoms in meteorites therefore provide information on the length of their journey from the asteroid belt to Earth, on the collision frequency in the asteroid belt, on preatmospheric sizes of meteorites and sometimes on processes on the parent body surface (Wieler 2002; Herzog 2003). It is commonly assumed in such studies that the intensity (and energy spectrum) of the GCR has remained constant - and hence that production rates of "cosmogenic" nuclides show no temporal variation. Comprehensive studies of cosmogenic nuclides in meteorites also have the potential, however, to test this very assumption. This is the main topic of this review. Because the concentration of a cosmogenic nuclide reflects the integral exposure history of a meteorite, only potential variations with a duration comparable to the half-lives of the considered cosmogenic radionuclides can be studied. Half-lives of relevant radionuclides range between a few years and $1.28 \mathrm{Ga}$, but much of the work discussed below deals with timescales of about $10^{6}-10^{9}$ years. Variations in this time range might well be expected to reflect variations in the interstellar GCR flux as opposed to flux changes in the heliosphere (Jokipii 1991).

Cosmogenic ${ }^{10} \mathrm{Be}$ and other radionuclides are also produced in the Earth's atmosphere and stored in archives such as ice cores, sediments or Fe-Mn nodules. These terrestrial records also have the potential to constrain variations in the interstellar GCR flux. Terrestrial ${ }^{10}$ Be thus may complement the meteorite record on times scales of up to $10^{7}$ years, if effects of secondary interest here (variable nodule growth rates etc.) can reliably be separated from production rate changes. Cosmogenic radionuclides in archives have the advantage to reflect instantaneous fluxes and hence provide a higher temporal resolution than meteorites. However, these records reflect not only the GCR intensity and solar modulation effects, but also changes in the geomagnetic dipole moment and climate effects induced by the transport of cosmogenic radionuclides from the atmosphere into their respective archives. We will also review this aspect of terrestrial ${ }^{10} \mathrm{Be}$ studies.

\section{Nuclide Production Rates in Meteorites}

Cosmogenic nuclides in meteorites are mainly produced by GCR particles with energies ranging from a few hundred $\mathrm{MeV}$ to a few $\mathrm{GeV}$ and their secondaries. Nuclide concentrations therefore depend on intensity and spectral shape of GCR particles in this energy interval. In the following we will implicitly assume a constant shape of the energy spectrum, however, and only talk about possible intensity variations.

Basically, GCR intensity variations are searched for by comparing concentrations of different suitable pairs of a stable and a radioactive nuclide. A classical way (e.g., Herzog and Anders 1971) is to determine first the production rate of a radioactive nuclide, which equals its saturation activity (the saturation concentration times the decay constant). The saturation concentration is reached in practice, i.e. to within better than $\sim 3 \%$, after an exposure of a meteorite to GCR during 5 half-lives. Hence one needs to identify a number of meteorites of a given chemical group (i.e., with the same concentrations of all relevant main target elements) with identical concentrations of the radionuclide considered. As discussed in more detail below, an important additional requirement is that one is able to correct for the dependency of the production rate on the "shielding" of a sample, which depends on 
its position within the meteorite in space (the "preatmospheric" meteorite) and the size of the preatmospheric meteorite. Next, for other meteorites of the same class which have not been exposed long enough for the radionuclide to have reached saturation, their radionuclide exposure ages can be calculated using the ingrowth curve. If this procedure will yield identical exposure ages determined by different radionuclides, one may conclude that the GCR flux averaged over the past few half-lives of all involved nuclides (the interval during which they reached their saturation concentration) has remained constant within the limits of uncertainty imposed by the method. Otherwise, either some assumption would have been violated or the average GCR flux would have varied over the timescales involved. In practice, however, only for very few meteorites precise exposure ages based on radionuclides with different half-lives can be determined simultaneously. This requires exposure ages to be long enough for sizeable concentrations of the longer-lived nuclide already to have built up but short enough that also the nuclide with the shorter half-life is still not close to its saturation concentration. Therefore, a stable cosmogenic nuclide (mostly a noble gas isotope) is usually also involved. Assuming a constant GCR intensity, a meteorite for which an exposure age based on a radionuclide has been determined yields also the production rate of stable nuclides, simply by dividing the stable nuclide concentration by the exposure age. This is the basis for empirical production rate determinations of stable nuclides and hence determinations of exposure ages longer than the range covered by radionuclides. Let us consider the case where the mean production rate of a given stable nuclide obtained from a number of suitable meteorites whose exposure ages were determined with one radionuclide is identical to the mean production rate obtained from another set of meteorites whose ages were obtained using another radionuclide. If so, again one may conclude that within the limits of uncertainty the GCR intensity during the past few half-lives of one nuclide has on average been the same as during the past few half-lives of the other nuclide. Otherwise, a variable GCR flux may be indicated. Intricacies such as corrections for production rate variations within a meteorite due to shielding or "complex" exposure histories are discussed below.

Radionuclides with half-lives shorter than a few hundred thousand years will be in saturation at the time of fall essentially in all meteorites, because exposure ages below a million years are very rare. For such a nuclide, the ratio of its production rate to that of a suitable stable nuclide has to be determined or inferred. Best suited are nuclide pairs where the stable nuclide is produced largely through the radionuclide. A good example is the pair ${ }^{36} \mathrm{Cl}-{ }^{36} \mathrm{Ar}$. In metallic iron-nickel, more than $80 \%$ (Lavielle et al. 1999) of the cosmogenic ${ }^{36} \mathrm{Ar}$ is produced through its radioactive precursor ${ }^{36} \mathrm{Cl}$ (half-life $0.301 \mathrm{Ma}$ ). Therefore, the production rate ratio $P\left({ }^{36} \mathrm{Ar}\right) / P\left({ }^{36} \mathrm{Cl}\right)$ is almost independent of the shielding of a sample (Leya et al. 2000) and the production rate of ${ }^{36} \mathrm{Ar}$ in a metallic iron-nickel sample (iron meteorites or metal separates from stony meteorites) can be determined by an analysis of ${ }^{36} \mathrm{Cl}$ in an aliquot sample. This has the great advantage that knowledge of the preatmospheric size of and the position of the sample within the meteorite is not required. To determine a ${ }^{36} \mathrm{Cl}-{ }^{36} \mathrm{Ar}$ age one assumes that the GCR intensity over the entire exposure duration given by the ${ }^{36} \mathrm{Ar}$ concentration has been the same as during the past few half-lives of ${ }^{36} \mathrm{Cl}$, i.e. the past 1-1.5 Ma. Other stable nuclides which have a suitable radioactive precursor are ${ }^{3} \mathrm{He}\left({ }^{3} \mathrm{H}\right)$ and ${ }^{22} \mathrm{Ne}\left({ }^{22} \mathrm{Na}\right)$, although in these cases the branching ratios between direct and indirect production are less well known (Begemann et al. 1957; Nishiizumi et al. 1980). Furthermore, radioactive ${ }^{81} \mathrm{Kr}\left(T_{1 / 2}=0.229 \mathrm{Ma}\right)$ can also be used to determine shieldingcorrected production rates of stable cosmogenic Kr isotopes in stony meteorites (Marti 1967; Herzog 2003), although ${ }^{81} \mathrm{Kr}$ is not a precursor of a stable $\mathrm{Kr}$ isotope. Yet, a single $\mathrm{Kr}$ isotope measurement provides ${ }^{81} \mathrm{Kr}-\mathrm{Kr}$ exposure ages, again based on the assumption that the 
GCR intensity throughout the exposure history of the meteorite and during the past $\sim 1 \mathrm{Ma}$ has been the same.

Another way to test the long term GCR flux with meteorites relies on calculating radionuclide production rates by physical modelling. Such models describe nuclide production based on nuclear physics codes and measured or calculated cross section data (Leya et al. 2000; Leya and Masarik 2009). The only free parameter is the incident GCR proton flux. If the same GCR flux does explain the measured saturation concentrations of radionuclides with different half-lives, the mean GCR flux would have remained constant-again within the uncertainties of the models and the data-during periods corresponding to the past few half-lives of the nuclides involved. Otherwise, long-term variations of the GCR flux would be indicated, if inadequacies of the models or the input data (cross sections) could be excluded.

A further method involves cosmogenic radioactive ${ }^{40} \mathrm{~K}$ in iron meteorites (Voshage and Hintenberger 1961; Herzog 2003; Lavielle et al. 1999). This method is being used to evaluate possible very long-term changes of the GCR intensity on time scales of up to $10^{9}$ years, as will be discussed in more detail later.

\section{The GCR Flux During the Past 10 Million Years as Recorded in Meteorites}

Apart from the special case of ${ }^{40} \mathrm{~K}\left(T_{1 / 2}=1.28 \mathrm{Ga}\right)$, the radionuclides most frequently used to evaluate the GCR flux in time with meteorites have half-lives on the order of a few hundred thousand to a few million years $\left({ }^{81} \mathrm{Kr}=0.229 \mathrm{Ma} ;{ }^{36} \mathrm{Cl}=0.301 \mathrm{Ma}\right.$; $\left.{ }^{26} \mathrm{Al}=0.72 \mathrm{Ma} ;{ }^{10} \mathrm{Be}=1.39 \mathrm{Ma} ;{ }^{53} \mathrm{Mn}=3.74 \mathrm{Ma}\right)$. This allows to study fluxes averaged over about 1-10 Ma. Sometimes, nuclides with much shorter half-lives are also considered $\left({ }^{22} \mathrm{Na}=2.6 \mathrm{a} ;{ }^{3} \mathrm{H}=12.3 \mathrm{a} ;{ }^{44} \mathrm{Ti}=59 \mathrm{a} ;{ }^{39} \mathrm{Ar}=269 \mathrm{a}\right)$ and the use of ${ }^{129} \mathrm{I}(15.7 \mathrm{Ma})$ is also being explored. Whereas ${ }^{40} \mathrm{~K}$ can exclusively be measured in iron meteorites, most of the work with the other nuclides is being done on stony meteorites.

As already mentioned, measured nuclide concentrations in a meteorite sample depend on its a priori unknown shielding, i.e., its depth below the surface of the preatmospheric meteorite and the size of this meteorite (e.g., Leya et al. 2000; Leya and Masarik 2009). Production rates of nuclides which are mainly produced by very high energy particles decrease steadily with increasing shielding, with an e-fold length in rocks of about $150 \mathrm{~g} / \mathrm{cm}^{2}$ or some $50 \mathrm{~cm}$. On the other hand, production rates of other nuclides decrease more slowly or even increase with depth near the surface, because they are largely the result of secondary cosmic ray neutrons which themselves were produced in the cascade of interactions of meteoritic matter with cosmic ray particles. These production systematics result in various semiquantitative "shielding indicators", an important example being the ratio ${ }^{22} \mathrm{Ne} /{ }^{21} \mathrm{Ne}$. Near a meteorite surface, this ratio decreases with increasing shielding, because the flux of energetic secondary neutrons increases with depth. The secondary neutrons produce relatively large amounts of ${ }^{21} \mathrm{Ne}$ through the reaction ${ }^{24} \mathrm{Mg}(n, \alpha){ }^{21} \mathrm{Ne}$. Shielding corrections of production rates via a semi-empirical shielding indicator (e.g., ${ }^{22} \mathrm{Ne} /{ }^{21} \mathrm{Ne}$ ) are non-unique, however (Leya et al. 2000; Leya and Masarik 2009), because, e.g., the same ${ }^{22} \mathrm{Ne} /{ }^{21} \mathrm{Ne}$ value can be produced at different depths in meteorites of different sizes. Therefore, such corrections will lead to some scatter in the data.

Several early studies reported differences in noble gas production rates based on different radionuclides (e.g., Herzog and Anders 1971; Cressy and Bogard 1976). A comprehensive evaluation of the ${ }^{21} \mathrm{Ne}$ production rate $(\mathrm{P} 21)$ determined via four different radionuclides $\left({ }^{22} \mathrm{Na},{ }^{81} \mathrm{Kr},{ }^{26} \mathrm{Al}\right.$, and $\left.{ }^{53} \mathrm{Mn}\right)$ from a large data set of chondritic meteorites was presented 
by Nishiizumi et al. (1980). In a similar study, Müller et al. (1981) determined P21 via ${ }^{26} \mathrm{Al}$ and ${ }^{53} \mathrm{Mn}$ measured in five chondrites with short exposure ages. Apart from shielding corrections via ${ }^{22} \mathrm{Ne} /{ }^{21} \mathrm{Ne}$, minor corrections were also applied in these and similar studies for the different major element compositions of different classes of chondritic meteorites, because the production rate of a nuclide is different for different target elements. Furthermore, ${ }^{22} \mathrm{Na}$ data were corrected by up to $15 \%$ for short-term GCR intensity variations induced by the solar activity cycle, according to the fall dates of the meteorites. Nishiizumi et al. (1980) found that P21 values based on the three nuclides ${ }^{22} \mathrm{Na},{ }^{81} \mathrm{Kr}$, and ${ }^{53} \mathrm{Mn}$, which have widely different half-lives, were identical within the uncertainties of 4-7\%. In contrast, P21 based on ${ }^{26} \mathrm{Al}$ was almost $70 \%$ higher than the average $\mathrm{P} 21$ determined by the other three radionuclides. Müller et al. (1981) observed similar absolute P21 $\left({ }^{26} \mathrm{Al}\right)$ and P21 $\left({ }^{53} \mathrm{Mn}\right)$ values as Nishiizumi et al. (1980) and hence a similar discrepancy. Both groups of authors considered various explanations for this discrepancy, including half-life errors (considered rather unlikely), minor concentrations of ${ }^{21} \mathrm{Ne}$ from a previous irradiation stage in some of the studied meteorites or a biased data selection, possibly leading, e.g., to imprecisely known saturation concentrations of certain nuclides or incorrect shielding corrections. Both groups also seriously considered a higher GCR intensity over most of the past $\sim 2 \mathrm{Ma}$, i.e., the time span during which most of the now extant ${ }^{26} \mathrm{Al}$ has been produced, relative to the longerterm average over the past $\sim 12 \mathrm{Ma}$ recorded by ${ }^{53} \mathrm{Mn}$. If so, however, the mean GCR activity during the last few hundred thousand years and the solar-activity-corrected mean during the last $\sim 10$ years would again had to have been similar to the $\sim 12 \mathrm{Ma}$ average represented by ${ }^{53} \mathrm{Mn}$, since also P21 derived via the two nuclides ${ }^{81} \mathrm{Kr}$ and ${ }^{22} \mathrm{Na}$ (which both have a shorter half-life than $\left.{ }^{26} \mathrm{Al}\right)$ are essentially identical to $\mathrm{P} 21\left({ }^{53} \mathrm{Mn}\right)$.

Later studies, however, indicated that a relatively late increase in the GCR flux is an unlikely explanation for the high apparent P21 $\left({ }^{26} \mathrm{Al}\right)$. Moniot et al. (1983) also observed a high $\mathrm{P} 21\left({ }^{26} \mathrm{Al}\right)$ value, but could hardly find a reasonable time dependence of the GCR flux able to reproduce the four P21 values derived from ${ }^{81} \mathrm{Kr},{ }^{26} \mathrm{Al},{ }^{10} \mathrm{Be}$ and ${ }^{53} \mathrm{Mn}$. These authors, as well as Vogt et al. (1993) suggested inappropriate shielding corrections (which would affect ${ }^{26} \mathrm{Al}$ more than ${ }^{10} \mathrm{Be}$ ) and complex exposure histories as most likely reasons for the discrepant $\mathrm{P} 21\left({ }^{26} \mathrm{Al}\right)$. In a study of iron meteorites discussed in more detail in a following section, Lavielle et al. (1999) obtained similar noble gas exposure age values based on production rates obtained from the three radionuclides ${ }^{36} \mathrm{Cl},{ }^{10} \mathrm{Be}$ and, in particular, ${ }^{26} \mathrm{Al}$. This study thus also argues against a variable mean GCR flux over the past $\sim 5 \mathrm{Ma}$, in agreement with earlier work on iron meteorites (Hampel and Schaeffer 1979). Yet another study arriving at the same conclusion is by Leya et al. (2000). These authors were able to simultaneously explain the concentration profiles of the radionuclides ${ }^{36} \mathrm{Cl},{ }^{26} \mathrm{Al},{ }^{10} \mathrm{Be}$ and ${ }^{53} \mathrm{Mn}$ in a large, comprehensively studied chondrite with the same cosmic ray proton flux, the only free parameter in their model of cosmogenic nuclide production.

In summary, more recent studies have not confirmed earlier suggestions of a higher mean GCR flux during the past few half-lives of ${ }^{26} \mathrm{Al}$ compared to both longer and shorter timescales. The meteorite record allows to conclude that, within limits of uncertainty discussed below, the GCR flux averaged over time scales of a few hundred thousand to a few million years remained constant. Also shorter-lived radionuclides $\left({ }^{22} \mathrm{Na},{ }^{3} \mathrm{H}\right.$ and $\left.{ }^{39} \mathrm{Ar}\right) \mathrm{com}-$ bined with stable noble gas isotope measurements indicate a constant average flux during the respective relevant time intervals of the past several years to several hundred years, if corrected for known variations in solar modulation (e.g. Hampel and Schaeffer 1979; Nishiizumi et al. 1980). A remarkable case for a GCR flux variation induced by a variable solar activity recorded in meteorites is ${ }^{44} \mathrm{Ti}$. Its decay-corrected concentration in meteorites fallen in the past 200 years varies in a way consistent with solar activity variations, reflecting the $\sim 88$ year Gleissberg cycle (Bonino et al. 1999). 


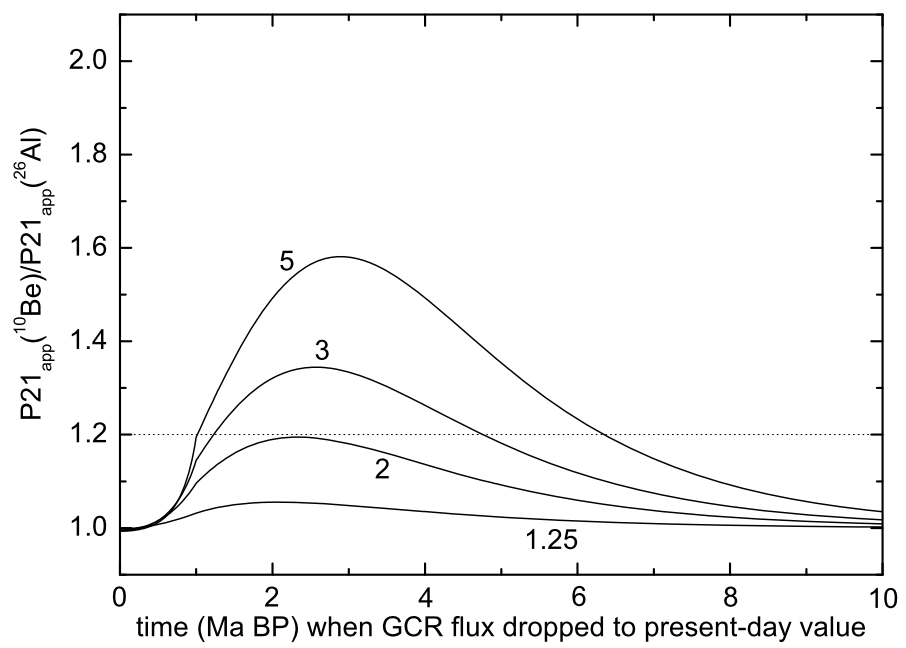

Fig. 1 The figure shows an example of the (limited) sensitivity of cosmogenic nuclide concentrations in meteorites to recognize potential cosmic ray flux changes in the past. The four curves show the ratio of apparent noble gas (e.g., ${ }^{21} \mathrm{Ne}$ ) production rates calculated via ${ }^{10} \mathrm{Be}$ and ${ }^{26} \mathrm{Al}$, respectively, assuming that the GCR flux in the past had been higher than today by the constant factors given as labels to the curves, and dropped instantaneously to present-day values at the time given on the abscissa. A further assumption is that apparent radionuclide production rates were determined by meteorites with a true exposure age of $10 \mathrm{Ma}$ and ${ }^{21} \mathrm{Ne}$ production rates by meteorites with a true exposure age of $1 \mathrm{Ma}$ (for both the ${ }^{21} \mathrm{Ne}-{ }^{10} \mathrm{Be}$ and ${ }^{21} \mathrm{Ne}-{ }^{26} \mathrm{Al}$ pair). The dotted line shows our assumed lower limit of $20 \%$ for apparent production rate differences to be recognizable. With this assumption, a GCR flux variation would be detectable by the different apparent production rates derived from the ${ }^{21} \mathrm{Ne}-{ }^{10} \mathrm{Be}$ and ${ }^{21} \mathrm{Ne}-{ }^{26} \mathrm{Al}$ pairs, respectively, if the flux had been higher than the present-day value by a factor of 5, and dropped to the present-day value between some 6.5 and $1 \mathrm{Ma}$ ago. A past flux higher by a factor of two would reach the detection limit if the drop to the present-day value would have happened about $2.5 \mathrm{Ma}$ ago

The power of the cosmogenic nuclide record in meteorites to reveal GCR flux variations requires a critical assessment, however. Limits of uncertainty for flux variations are often stated to be on the order of 20-30\%. However, this usually reflects only analytical or model uncertainties, half-life errors, data scatter, e.g., due to inaccurate shielding corrections etc. Note, e.g., that the ${ }^{10} \mathrm{Be}$ half-life has been revised downwards by $\sim 15 \%$ since the first studies cited above were published, without that this would require to change the basic conclusions noted above. However, because a measured radionuclide concentration in a meteorite reflects its integral production and decay during the past few half-lives, the detection limits for the magnitude of a hypothetical GCR flux change depend both on its duration as well as when it would have happened. Figure 1 illustrates in one example the limited sensitivity of the cosmogenic nuclide record in meteorites to detect potential GCR flux changes. For example, the combined pairs ${ }^{21} \mathrm{Ne}-{ }^{10} \mathrm{Be}$ and ${ }^{21} \mathrm{Ne}-{ }^{26} \mathrm{Al}$ alone would not be sufficiently sensitive to detect a 25\% drop in the GCR flux at any time before the present, even with a considerably better data base than that available. Note, however, that the available P21 estimates derived from very short-lived radionuclides (not shown in the figure) improve the sensitivity of the meteorite record for very recent potential GCR flux changes. Similarly, considering the entire available data base discussed above leads to an improved ability to recognize potential GCR flux changes than is indicated by the one example in the figure. Yet, because of the limited sensitivity of the time-integrated GCR signals provided 
by meteorites, it is wise to consider in the following section also the differential GCR flux signals provided by terrestrial sediment samples.

\section{The GCR Flux over the Past $\sim 10$ Million Years-Evidence from ${ }^{10} \mathrm{Be}$ in Terrestrial Samples}

Concentrations of cosmogenic ${ }^{10} \mathrm{Be}$ as a function of depth or deposition time are being measured in ice cores (Beer et al. 2011, this issue), as well as in marine sediments and slowly growing iron-manganese crusts, often in conjunction with stable ${ }^{9} \mathrm{Be}(\mathrm{Ku}$ et al. 1982; Bourlès et al. 1989; Frank et al. 1999, 2008; Willenbring and von Blanckenburg 2010). Some of these records have a high time resolution on the order of decades to thousands of years and typically cover the last few hundred thousand years. Other records date back to some $10 \mathrm{Ma}$ or about seven half-lives of ${ }^{10} \mathrm{Be}$. The high-resolution records typically are interpreted to reflect ${ }^{10} \mathrm{Be}$ production rate changes induced by a variable geomagnetic field or solar modulation (e.g., Christl et al. 2007). The long-term records are commonly used to derive sedimentation rates or growth rates of Fe-Mn crusts (Frank et al. 2008; Ling et al. 1997), as variabilities induced by geomagnetic field or solar modulation are thought to average out over these timescales. The common assumption in such studiesoften not explicitly stated-is that the primary GCR intensity has remained constant. Although for each individual record it may often be impossible to distinguish effects such as GCR modulation caused by the solar or the terrestrial magnetic fields, changing sedimentation rates or changing inputs of stable ${ }^{9} \mathrm{Be}$ from a potential GCR flux change, a global survey of available long-term records allows us to test the assumption of a constant GCR flux. This is discussed in the following.

The long-term records often show essentially an exponential decrease of the ${ }^{10} \mathrm{Be}$ concentration with depth in the sediment column or the Fe-Mn crust (usually after normalisation to a "constant flux proxy" such as ${ }^{9} \mathrm{Be}$ or ${ }^{230} \mathrm{Th}$ ). In one of the first detailed studies on a marine sediment core, Bourlès et al. (1989) noted, however, that the decrease of ${ }^{10} \mathrm{Be}$ with depth in this core independently dated by magnetostratigraphy was larger than expected from radioactive decay of ${ }^{10} \mathrm{Be}$ alone. One of the potential explanations considered was a gradual increase in the ${ }^{10} \mathrm{Be}$ production rate by a factor of $\sim 2$ in the past $9 \mathrm{Ma}$, possibly due to an increasing primary cosmic ray intensity. The authors also observed, however, that the decrease of the ${ }^{10} \mathrm{Be} /{ }^{9} \mathrm{Be}$ ratio of the total beryllium in the core (rather than the fraction associated only to "authigenic" minerals grown during the core sedimentation process which they otherwise would have preferred) corresponded to an effective ${ }^{10} \mathrm{Be}$ half-life of 1.43 Ma, which was close to the then accepted half-life of $1.51 \mathrm{Ma}$ and which is even closer to the currently accepted half-life of 1.39 Ma. They concluded that further work was needed to clarify the issue. A reanalysis of the data by Bourlès et al. (1989) has recently been made by Willenbring and von Blanckenburg (2010; their online appendix) with a modified magnetostratigraphic age scale of the core and the new ${ }^{10} \mathrm{Be}$ half-life. These authors did not recognize a time dependence of the initial ${ }^{10} \mathrm{Be} /{ }^{9} \mathrm{Be}$ ratio in these data. Hence this reanalysis shows that this core indicates no long-term variability in the ${ }^{10} \mathrm{Be}$ production rate and thus the GCR intensity.

Most ${ }^{10} \mathrm{Be}$ records lack an independent age control and therefore are not suitable to study potential smooth (more or less linear) long-term variations in the ${ }^{10} \mathrm{Be}$ production rate. Such variations would result in too high or too low apparent sedimentation or crust growth rates, which could not be recognized. However, as stated above, in many marine records the ${ }^{10} \mathrm{Be}$ concentrations decrease exponentially with depth, or sometimes data points of one record 
follow two or three different exponential decay curves in different growth intervals. In these cases the most simple and most reasonable assumption is that sedimentation or crust growth rates and initial ${ }^{10} \mathrm{Be}$ concentrations-hence the average GCR flux over the time scales given by the record's time resolution-have remained constant (or constant within a given time interval) within the limits of uncertainty given by the scatter of the data points. Initial ${ }^{10} \mathrm{Be} /{ }^{9} \mathrm{Be}$ ratios for various marine records have been compiled, e.g., by Frank (2002) and Willenbring and von Blanckenburg (2010). In many cases, the individual data points scatter around the average by a few $10 \%$, with occasional larger deviations of typically up to factors of 2-3. Therefore, an individual record would constrain the GCR intensity averaged over typically a few hundred thousand years to have mostly remained constant within a few $10 \%$, with the possibility of occasionally larger variations of up to a factor of 3 . However, none of the spikes in one record is conspicuous in other records, indicating that they rather reflect local phenomena.

Similarly, also smaller deviations from the average seen in some records are hardly reproduced in other records. We calculated for each data point of the eight records shown by Willenbring and von Blanckenburg (2010) the deviation from the average ${ }^{10} \mathrm{Be} /{ }^{9} \mathrm{Be}$ ratio of the respective record, and grouped all data in bins of $0.5 \mathrm{Ma}$ width, back to $10 \mathrm{Ma}$ ago. Standard deviations within single records are sometimes as low as $10 \%$ and never exceed $\sim 30 \%$, if the few outliers are excluded. All eight records combined yield a standard deviation of $11 \%$, already indicating that the GCR intensity averaged over $0.5 \mathrm{Ma}$ has not varied by more than $\pm 20 \%$. With one exception, however, in none of the $0.5 \mathrm{Ma}$ intervals do the initial ${ }^{10} \mathrm{Be} /{ }^{9} \mathrm{Be}$ ratios in different records vary with time in a correlated way, indicating that the $\pm 20 \%$ variations are hardly caused by a global variation of the ${ }^{10}$ Be production rate. The exception is the interval between 2.5-4.5 Ma ago, where the initial ${ }^{10} \mathrm{Be} /{ }^{9} \mathrm{Be}$ ratios are lower than their record-average by $10-30 \%$ in 6 out of 8 records. However, this should hardly be taken as convincing evidence for a decrease of the global ${ }^{10} \mathrm{Be}$ production rate and the global primary GCR flux by some $20 \%$ between $\sim 2.5-4.5 \mathrm{Ma}$ ago. First, it would then remain unexplained why two of the records considered here do not show this decrease. Second, neither does another set of initial ${ }^{10} \mathrm{Be} /{ }^{9} \mathrm{Be}$ ratios compiled by Frank (2002) show a dip between 2.5-4.5 Ma ago.

In summary, we therefore conclude that the terrestrial ${ }^{10} \mathrm{Be}$ records taken together indicate on the one hand that the global ${ }^{10} \mathrm{Be}$ production rate and hence the GCR intensity has not varied gradually in the past $10 \mathrm{Ma}$. On the other hand, the shorter-term $(0.5 \mathrm{Ma})$ average GCR intensity has also remained constant within better than perhaps $\pm 10 \%$. The terrestrial data therefore considerably strengthen the conclusions drawn above from meteorite studies.

\section{The GCR Flux over the Past $\sim 1000$ Million Years-Evidence from Iron Meteorites}

Potassium-40 has a half-life of $1277 \mathrm{Ma}$, much longer than any other radionuclide discussed here. Conventionally, ${ }^{40} \mathrm{~K}$ and its daughter ${ }^{40} \mathrm{Ar}$ are used to date formation or metamorphic ages of rocks. However, in iron meteorites native potassium is so rare that the cosmic-rayproduced fractions of the $\mathrm{K}$ isotopes can be determined. Due to their larger mechanical strength, iron meteorites are less susceptible to collisional destruction than stony meteorites. Therefore, many iron meteorites have exposure ages of up to about a billion years. The ${ }^{40} \mathrm{~K}-\mathrm{K}$ exposure dating system has thus the potential to explore the long-term average cosmic ray flux over about the past $10^{9}$ years. The method has been pioneered by $\mathrm{H}$. Voshage (Voshage and Hintenberger 1961; Voshage 1984). Similar to other methods described above, it relies on the combination of a cosmogenic radionuclide $\left({ }^{40} \mathrm{~K}\right)$ with stable cosmogenic nuclides $\left({ }^{39} \mathrm{~K}\right.$ and $\left.{ }^{41} \mathrm{~K}\right)$. However, ${ }^{40} \mathrm{~K}-\mathrm{K}$ dating faces several additional difficulties (cf. Herzog 
2003). For example, the production rate of ${ }^{40} \mathrm{~K}$ cannot directly be measured, as no meteorites exist with exposure ages long enough for this isotope to reach saturation. The large size of many iron meteorites also makes shielding corrections even more critical than for stony meteorites. Moreover, only isotopic ratios $\left({ }^{39} \mathrm{~K} /{ }^{40} \mathrm{~K}\right.$ and $\left.{ }^{41} \mathrm{~K} /{ }^{40} \mathrm{~K}\right)$ can be measured, rather than absolute concentrations. Finally, the lack of measured cross section data poses a problem for production rate determinations. Despite these complications, H. Voshage assembled a large data set of about $80{ }^{40} \mathrm{~K}-\mathrm{K}$ exposure ages of iron meteorites $>100 \mathrm{Ma}$, the lower limit for which precise ages could be obtained (Voshage 1984).

These ages can be compared with exposure ages of (subsets of) the same meteorites calibrated with other, shorter-lived radionuclides. Lavielle et al. (1999) did this on a subset of 13 meteorites using the ${ }^{36} \mathrm{Cl}-{ }^{36} \mathrm{Ar}$, the ${ }^{26} \mathrm{Al}-{ }^{21} \mathrm{Ne}$ and the ${ }^{10} \mathrm{Be}-{ }^{21} \mathrm{Ne}$ systems. Earlier, Hampel and Schaeffer (1979) and Aylmer et al. (1988) had already compared ${ }^{40} \mathrm{~K}-\mathrm{K}$ ages with ages based on ${ }^{10} \mathrm{Be},{ }^{26} \mathrm{Al},{ }^{36} \mathrm{Cl}$, and ${ }^{39} \mathrm{Ar}$. While in all these studies the ages based on all shorter-lived nuclides agreed with each other within experimental uncertainties, the ${ }^{40} \mathrm{~K}-\mathrm{K}$ ages were about $35-50 \%$ higher than the former ages. The most straightforward explanation for this difference appeared to be an increase in the GCR intensity in the past several million years relative to the long-term average over the past 500-1000 Ma, although Lavielle et al. (1999) cautioned that current uncertainties in the production systematics of cosmogenic K nuclei prevent a clear conclusion.

A recent attempt to improve our understanding of the production systematics of $\mathrm{K}$ and other nuclides has been done by Ammon et al. (2009). These authors calculated nuclide production rates in iron meteorites using a physical model and compared the modelled rates with extensive data sets measured throughout cross sectional areas of two large iron meteorites. This study does not confirm the previous conclusion of a higher GCR intensity in the past few million years relative to the long term average. For one of the two studied meteorites, the ${ }^{40} \mathrm{~K}-\mathrm{K}$ age agrees well with ages calibrated with shorter-lived nuclides, whereas for the other meteorite, the ${ }^{40} \mathrm{~K}-\mathrm{K}$ age is about $40 \%$ lower than the other ages. Hence, if anything, this work might suggest a lower-rather than a higher-GCR intensity in the past few million years relative to the several hundred million year average. However, the model uncertainties are large enough to prevent a determination of a possible difference between the few Ma and the Ga average of the cosmic ray flux on a level of better than some $40 \%$. Expressed the other way round, however, the iron meteorite data base shows that the GCR intensity averaged over the past few million years has been the same as the long-term average in the past 500-1000 Ma within a factor of about 1.5.

A 150 Ma periodicity of the GCR intensity recorded in iron meteorites? In a series of papers, N.J. Shaviv argued that cosmogenic nuclides in iron meteorites provide evidence for a fluctuation of the GCR intensity with a periodicity of $147 \pm 6$ Ma (Shaviv 2002, 2003; Scherer et al. 2006). This is taken to reflect the periodic passage of the solar system through spiral arms in the Galaxy. There, star formation and supernova rates are higher, which is thought to lead to a higher local GCR flux. The presumed periodicity of the GCR flux has been linked to the occurrence of ice age epochs on Earth, which are proposed to be triggered, e.g., by a larger global cloud coverage during times of high GCR intensity (Shaviv 2003; Shaviv and Veizer 2003). Here we examine the postulated evidence for a periodic variability of the GCR intensity.

The basic idea is that if the GCR intensity varies periodically, the distribution of apparent exposure ages of iron meteorites - calculated with the assumption of a constant GCR flux and energy spectrum - should exhibit periodic peaks. During times of low GCR intensity, the "cosmic ray clock" would tick slower, leading to a clustering of apparent exposure ages around epochs of low GCR flux (e.g., Scherer et al. 2006). An important assumption is that 
the actual delivery rate of iron meteorites to Earth either remains constant or that peaks in the actual exposure age distribution due to large collisions in the asteroid belt can reliably be corrected for.

Because only ratios of production rates of $\mathrm{K}$ isotopes appear in the equation for ${ }^{40} \mathrm{~K}-\mathrm{K}$ ages (cf. Herzog 2003), it is not trivial to expect that a variable GCR intensity should influence calculated potassium exposure ages. We tested this by producing an artificial data set assuming a meteorite population irradiated with a GCR flux varying as proposed by Shaviv (2003). Randomly selecting 40 meteorites (corresponding to the actual independent iron meteorite data base; see below) yielded apparent exposure age histograms (not shown) roughly reflecting the presumed GCR flux variation. A variable flux, if it existed, should therefore indeed be reflected in the iron meteorite data, contrary to the assertion by Ammon et al. (2009) that ${ }^{40} \mathrm{~K}-\mathrm{K}$ exposure ages are independent of the GCR flux.

As noted above, a crucial assumption is that the actual infall rate of the iron meteorites selected has remained constant over the past $\sim 10^{9}$ years. However, the delivery rate of stony meteorites is dominated for many groups by one or a few single large collisions in the asteroid belt. For example, almost half of all H-chondrites (one of the largest meteorite groups, representing $\sim 30 \%$ of all meteorite falls) have a cosmic ray exposure age of $\sim 7 \mathrm{Ma}$ (Marti and Graf 1992). This means that about $15 \%$ of all meteorites falling to Earth today are the result of one single collision in the asteroid belt some $7 \mathrm{Ma}$ ago. Similar exposure age peaks are known for many other stony meteorite classes (e.g. Marti and Graf 1992; Eugster and Michel 1995). A very major asteroid break-up event, which led to a temporary increase in the meteorite delivery rate to Earth by some two orders of magnitude, is also documented by fossil stony meteorites in 470 Ma old marine sediments (Schmitz et al. 1997). Nevertheless, on an individual level it is often difficult to clearly identify sourcepaired meteorites, due to analytical uncertainties and the possibility of complex exposure histories.

Here we rely on the $\sim 80{ }^{40} \mathrm{~K}-\mathrm{K}$ exposure ages of iron meteorites compiled by Voshage and Hintenberger (1961), Voshage and Hess (1964), Voshage (1978), and Voshage and Feldmann (1979). For meteorites for which more than one age has been published, we usually chose the latest datum, which often also has the smallest uncertainty. Despite the rather scarce data base, two major peaks have been recognized. Most of the dated meteorites from two of the largest iron meteorite classes (IIIAB \& IVA) each cluster in one single exposure age interval, at $\sim 550-750 \mathrm{Ma}$ and $\sim 350-500 \mathrm{Ma}$, respectively (Voshage 1978; Wieler 2002). These clusters are commonly interpreted to be the result of two large collisions, and the rather wide range of nominal ages to reflect overall uncertainties of ${ }^{40} \mathrm{~K}-\mathrm{K}$ exposure age determinations. Therefore, $\sim 25$ of $\sim 80$ dated iron meteorites again may represent just two single collisions and in this analysis should then only count as two individual samples. No other source-pairings for iron meteorites have been recognized, although the example of the large classes IIIAB and IVA suggests that clusters may well exist also among the smaller classes. In his analysis, Shaviv (2003) attempted to avoid multiple countings of clustered meteorites by merging meteorites with the same classification and exposure ages separated by less than $100 \mathrm{Ma}$.

Our own analysis of the ${ }^{40} \mathrm{~K}-\mathrm{K}$ exposure age distribution of iron meteorites is basically similar to that of Shaviv (2003). We follow the classification scheme of Keil et al. (1994) and Burbine et al. (2002), who list 13 major groups. In particular, IIIA and IIIB meteorites are merged into group IIIAB. Within each group or grouplet, we considered all meteorites with ages identical within $100 \mathrm{Ma}$ or within the stated age uncertainties to derive from one collision in the asteroid belt. This results in 38 independent events, less than the 50 events defined by Shaviv (2003). The histogram in Fig. 2 shows the resulting exposure age 


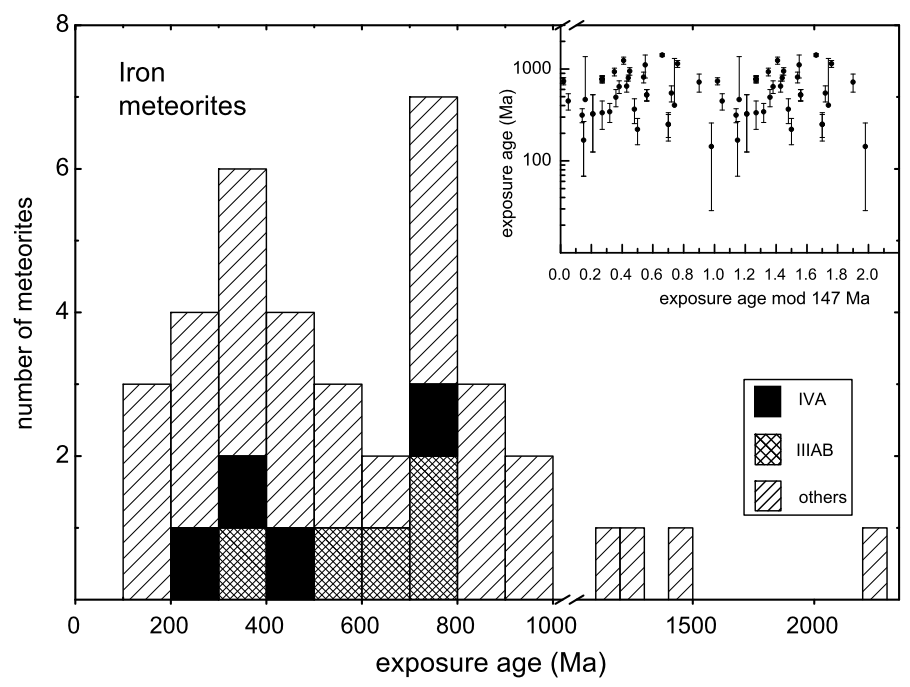

Fig. 2 Main panel: Histogram of ${ }^{40} \mathrm{~K}-\mathrm{K}$ cosmic-ray exposure ages of 38 independent iron meteorite falls as defined in the text. The IVA and IIIAB groups are shown separately. The bin size of 100 Ma roughly corresponds to the average uncertainty of the individual ages. No $\sim 150$ Ma periodicity is observed (nor would such a periodicity show up in a histogram with a narrower bin size of $50 \mathrm{Ma}$, not shown). The reality of the two apparent peaks at 300-400 Ma and 700-800 Ma is unclear, as statistics are poor. Data sources are given in the text. Inset: The exposure ages of the same sample set (ordinate, including uncertainties taken from original data sources) plotted modulo $147 \mathrm{Ma}$, following Scherer et al. (2006). Two periods are shown, for clarity. Unlike Scherer et al. (2006), we do not observe a clear 147 Ma periodicity in this diagram

distribution. Two peaks centered at $\sim 300-400$ Ma and $\sim 700-800$ Ma appear to be present, although the number of events is small. The peaks may be reminiscent of those defined by the two large groups IIIAB and IVA in the overall iron meteorite age histograms mentioned above, although the respective peak centers are shifted towards each other by $~ 50-100 \mathrm{Ma}$. However, at best three of the remaining independent events in the IVA group contribute to the first peak, and similarly, the second peak encompasses only two independent IIIAB events. We therefore conclude that the two peaks in Fig. 2 are unrelated to the two collisional events which produced the large majority of the IIIAB and IVA iron meteorites. The statistical significance of the two peaks is unclear.

The most important observation in Fig. 2 with respect to this paper is, however, the lack of a $\sim 150$ Ma periodicity in the exposure age histogram. In order to check this postulated periodicity further, we follow Scherer et al. (2006) and plot the ages modulo $147 \mathrm{Ma}$ (Fig. 2, inset). Unlike Scherer et al. (2006) we do not recognize an unambiguous gap at the full period. This diagram may further be biased by a complete lack of dated iron meteorites with K-exposure ages <100 Ma (Voshage 1984). We therefore conclude that exposure ages of iron meteorites do not provide firm evidence for a $\sim 150$ Ma periodicity of the GCR flux. The available data base would also be rather inadequate to reveal such a periodicity, should it exist. Not only is the number of dated iron meteorites quite small. The two rather broad exposure age peaks of groups IIIAB and IVA also illustrate the large uncertainties of iron meteorite exposure ages, leading to ambiguities to identify source-paired meteorites. This is particularly difficult for the smaller groups of iron meteorites, for each of which only a few individual meteorites have been analysed. 
Acknowledgements We thank Friedhelm von Blanckenburg for discussions and Veronika S. Heber for her comprehensive review of this manuscript.

\section{References}

K. Ammon, J. Masarik, I. Leya, New model calculations for the production rates of cosmogenic nuclides in iron meteorites. Meteorit. Planet. Sci. 44, 485-503 (2009)

D. Aylmer, V. Bonanno, G.F. Herzog, H. Weber, J. Klein, R. Middleton, ${ }^{26} \mathrm{Al}$ and ${ }^{10}$ Be production in iron meteorites. Earth Planet. Sci. Lett. 88, 107-118 (1988)

J. Beer et al., Space Sci. Rev. (2011, this issue)

F. Begemann, J. Geiss, D.C. Hess, Radiation age of a meteorite from cosmic-ray-produced $\mathrm{He}^{3}$ and $\mathrm{H}^{3}$. Phys. Rev. 107, 540-542 (1957)

G. Bonino, G. Cini Castagnoli, N. Bhandari, P. Della Monica, C. Taricco, Galactic cosmic ray variations in the last two centuries recorded by cosmogenic ${ }^{44} \mathrm{Ti}$ in meteorites. Adv. Space Res. 23, 607-610 (1999)

D. Bourlès, G.M. Raisbeck, F. Yiou, ${ }^{10} \mathrm{Be}$ and ${ }^{9} \mathrm{Be}$ in marine sediments and their potential for dating. Geochim. Cosmochim. Acta 53, 443-452 (1989)

T.H. Burbine, T.J. McCoy, A. Meibom, B. Gladman, K. Keil, Meteoritic parent bodies: their number and identification, in Asteroids III, ed. by W.F. Bottke et al. (Univ. Arizona Press, Tucson, 2002), pp. 653667

M. Christl, A. Mangini, P.W. Kubik, Highly resolved Beryllium-10 record from ODP Site 1089—A global signal? Earth Planet. Sci. Lett. 257, 245-258 (2007)

P.J. Cressy, D.D. Bogard, On the calculation of cosmic-ray exposure ages of stone meteorites. Geochim. Cosmochim. Acta 40, 749-762 (1976)

O. Eugster, T. Michel, Common asteroid break-up events of eucrites, diogenites, and howardites and cosmicray production rates for noble gases in achondrites. Geochim. Cosmochim. Acta 59, 177-199 (1995)

M. Frank, Radiogenic isotopes: tracers of past ocean circulation and erosional input. Rev. Geophys. 40, 1001 (2002). doi:10.1029/2000RG000094

M. Frank, J. Backman, M. Jakobsson, K. Moran, M. O’Regan, J. King, B.A. Haley, P.W. Kubik, D. Garbe-Schonberg, Beryllium isotopes in central Arctic Ocean sediments over the past 12.3 million years: stratigraphic and paleoclimatic implications. Paleoceanography 23, PA1S02 (2008). doi:10.1029/2007PA001478

M. Frank, R.K. O’Nions, J.R. Hein, V.K. Banakar, 60 Myr records of major elements and Pb-Nd isotopes from hydrogenous ferromanganese crusts: reconstruction of seawater paleochemistry. Geochim. Cosmochim. Acta 63, 1689-1708 (1999)

W. Hampel, O.A. Schaeffer, ${ }^{26} \mathrm{Al}$ in iron meteorites and the constancy of cosmic ray intensity in the past. Earth Planet. Sci. Lett. 42, 348-358 (1979)

G.F. Herzog, Exposure ages of stony and of stony-iron meteorites, in Treatise on Geochemistry, ed. by A.M. Davis, vol. 1 (Elsevier, Oxford, 2003), pp. 347-380

G.F. Herzog, E. Anders, Absolute scale for radiation ages of stony meteorites. Geochim. Cosmochim. Acta 35, 605-611 (1971)

J.R. Jokipii, Variations of the cosmic-ray flux with time, in The Sun in Time, ed. by C.P. Sonnett, M.S. Giampapa, M.S. Matthews (Univ. Arizona Press, Tucson, 1991), pp. 205-220

K. Keil, H. Haack, E.R.D. Scott, Catastrophic fragmentation of asteroids: evidence from meteorites. Planet. Space Sci. 42, 1109-1122 (1994)

T.L. Ku, M. Kusakabe, D.E. Nelson, J.R. Southon, R.G. Korteling, J. Vogel, I. Nowikow, Constancy of oceanic deposition of ${ }^{10} \mathrm{Be}$ as recorded in manganese crusts. Nature 299, 240-242 (1982)

B. Lavielle, K. Marti, J.P. Jeannot, K. Nishiizumi, M. Caffee, The ${ }^{36} \mathrm{Cl}-{ }^{36} \mathrm{Ar}-{ }^{40} \mathrm{~K}-{ }^{41} \mathrm{~K}$ records and cosmic ray production rates in iron meteorites. Earth Planet. Sci. Lett. 170, 93-104 (1999)

I. Leya, H.-J. Lange, S. Neumann, R. Wieler, R. Michel, The production of cosmogenic nuclides in stony meteoroids by galactic cosmic-ray particles. Meteorit. Planet. Sci. 35, 259-286 (2000)

I. Leya, J. Masarik, Cosmogenic nuclides in stony meteorites revisited. Meteorit. Planet. Sci. 44, 1061-1086 (2009)

H.F. Ling, K.W. Burton, R.K. O’Nions, B.S. Kamber, F. von Blanckenburg, A.J. Gibb, J.R. Hein, Evolution of $\mathrm{Nd}$ and $\mathrm{Pb}$ isotopes in central Pacific seawater from ferromanganese crusts. Earth Planet. Sci. Lett. 146, 1-12 (1997)

K. Marti, Mass-spectrometric detection of cosmic-ray-produced $\mathrm{Kr}^{81}$ in meteorites and the possibility of Kr-Kr dating. Phys. Rev. Lett. 18, 264-266 (1967)

K. Marti, T. Graf, Cosmic-ray exposure history of ordinary chondrites. Annu. Rev. Earth Planet. Sci. 20, 221-243 (1992) 
R.K. Moniot, T.H. Kruse, C. Tuniz, W. Savin, G.S. Hall, T. Milazzo, D. Pal, G.F. Herzog, The ${ }^{21}$ Ne production rate in stony meteorites estimated from ${ }^{10} \mathrm{Be}$ and other radionuclides. Geochim. Cosmochim. Acta 47, 1887-1895 (1983)

O. Müller, W. Hampel, T. Kirsten, G.F. Herzog, Cosmic-ray constancy and cosmogenic production rates in short-lived chondrites. Geochim. Cosmochim. Acta 45, 447-460 (1981)

K. Nishiizumi, S. Regnier, K. Marti, Cosmic ray exposure ages of chondrites, pre-irradiation and constancy of cosmic ray flux in the past. Earth Planet. Sci. Lett. 50, 156-170 (1980)

K. Scherer, H. Fichtner, T. Borrmann, J. Beer, L. Desorgher, E. Flükiger, H.J. Fahr, S.E.S. Ferreira, U.W. Langner, M.S. Potgieter, B. Heber, J. Masarik, N.J. Shaviv, J. Veizer, Interstellar-terrestrial relations: variable cosmic environments, the dynamic heliosphere, and their imprints on terrestrial archives and climate. Space Sci. Rev. 127, 327-465 (2006)

B. Schmitz, B. Peucker-Ehrenbrink, M. Lindström, M. Tassinari, Accretion rates of meteorites and cosmic dust in the early ordovician. Science 278, 88-90 (1997)

N.J. Shaviv, Cosmic ray diffusion from the galactic spiral arms, iron meteorites, and a possible climatic connection (vol. 89, art. no. 051102, 2002). Phys. Rev. Lett. 89, art. no.-089901 (2002). doi:10.1103/PhysRevLett.89.051102

N.J. Shaviv, The spiral structure of the Milky Way, cosmic rays, and ice age epochs on Earth. New Astron. 8, 39-77 (2003)

N.J. Shaviv, J. Veizer, Celestial driver of phanerozoic climate? GSA today July 2003, 4

S.K. Vogt, D. Aylmer, G.F. Herzog, R. Wieler, P. Signer, P. Pellas, C. Fiéni, C. Tuniz, A.J.T. Jull, D. Fink, J. Klein, R. Middleton, On the Bur Gheluai H5 chondrite and other meteorites with complex exposure histories. Meteoritics 28, 71-85 (1993)

H. Voshage, Investigations on cosmic-ray-produced nuclides in iron meteorites, 2. New results on ${ }^{41} \mathrm{~K} /{ }^{40} \mathrm{~K}-{ }^{4} \mathrm{He} /{ }^{21} \mathrm{Ne}$ exposure ages and the interpretations of age distributions. Earth Planet. Sci. Lett. 40, 83-90 (1978)

H. Voshage, Investigations of cosmic-ray-produced nuclides in iron meteorites, 6. The Signer-Nier model and the history of the cosmic radiation. Earth Planet. Sci. Lett. 71, 181-194 (1984)

H. Voshage, H. Hintenberger, Massenspektrometrische Isotopenhäufigkeitsmessungen an Kalium aus Eisenmeteoriten und das Problem der Bestimmung der ${ }^{41} \mathrm{~K}-{ }^{40} \mathrm{~K}-$ Strahlungsalter. Z. Naturforsch. 16a, 10421053 (1961)

H. Voshage, D.C. Hess, Strahlungsalter einiger Eisenmeteorite. Z. Naturforsch. 19a, 341-346 (1964)

H. Voshage, H. Feldmann, Investigations on cosmic-ray-produced nuclides in iron meteorites, 3. Exposure ages, meteoroid sizes and sample depths determined by mass spectrometric analyses of potassium and rare gases. Earth Planet. Sci. Lett. 45, 293-308 (1979)

R. Wieler, Cosmic-ray-produced noble gases in meteorites. Rev. Mineral. Geochem. 47, 125-170 (2002)

J.K. Willenbring, F. von Blanckenburg, Long-term stability of global erosion rates and weathering during late-Cenozoic cooling. Nature 465, 211-214 (2010) 